\title{
Case fatality rates after first acute coronary syndrome in persons treated for type 2 diabetes show an improving trend
}

\author{
K. M. Winell • R. Pääkkönen • A. Pietilä • M. K. Niemi • \\ A. R. Reunanen $\cdot$ V. V. Salomaa
}

Received: 3 March 2009 / Accepted: 5 October 2009 /Published online: 9 December 2009

(C) Springer-Verlag 2009

\begin{abstract}
Aims/hypothesis We analysed whether the prognosis of a first acute coronary syndrome (ACS) in patients treated for type 2 diabetes has improved. We also compared the trends in patients with and without diabetes.

Methods We used national registers to identify all patients with clinically known type 2 diabetes in Finland during the years 1988 to $2002(n=222,940)$. All first-ever ACS events $(n=43,412)$ among these patients were identified using the Hospital Discharge Register and the Causes of Death Register. From the National Cardiovascular Disease Register we identified all first ACS attacks $(n=191,403)$ among non-diabetic patients in the country. Finally, we calculated annual age-standardised case fatality rates for ACS for three time periods: prehospital, days 0 to 27 and days 28 to 364 after the first ACS.

Results The case fatality rate of first ACS declined significantly in both sexes at all time points considered. The declining trends were not different between patients with type 2 diabetes and those without. Among men aged 35 to 74 years, $58.5 \%$ (95\% CI $57.6-59.4 \%)$ with type 2 diabetes and $44.1 \%$ (95\% CI 43.8-44.5\%) without diabetes had died from cardiovascular causes 1 year after their first ACS. Among women of the same age, the corresponding figures were $54.2 \%$ (95\% CI $53.0-55.4 \%)$ and $36.5 \%$ (95\% CI $35.9-37.1 \%)$. Men generally had higher case fatality rates than women. However, except for prehospital deaths,
\end{abstract}

Electronic supplementary material The online version of this article (doi:10.1007/s00125-009-1606-2) contains supplementary material, which is available to authorised users.

K. M. Winell $(\bowtie) \cdot$ R. Pääkkönen · A. Pietilä • M. K. Niemi •

A. R. Reunanen · V. V. Salomaa

National Institute for Health and Welfare,

POB 30, 00271 Helsinki, Finland

e-mail: klas.winell@conmedic.fi diabetic women had the same or even higher case fatality rates than non-diabetic men.

Conclusions/interpretation The case fatality rates for first ACS show similar improving trends in patients with type 2 diabetes and in those without. However, case fatality rates have remained higher in patients with type 2 diabetes.

Keywords Acute coronary syndrome · Case fatality Time trends · Type 2 diabetes mellitus

$\begin{array}{ll}\text { Abbreviations } \\ \text { ACS } & \text { Acute coronary syndrome } \\ \text { CVD } & \text { Cardiovascular disease } \\ \text { ICD } & \text { International Classification of Diseases } \\ \text { ID } & \text { Identification code } \\ \text { MONICA } & \begin{array}{l}\text { Monitoring Trends and Determinants on } \\ \text { Cardiovascular Diseases }\end{array}\end{array}$

\section{Introduction}

Diabetes mellitus, especially type 2 diabetes, is becoming more and more common [1, 2]. In Finland, the number of persons treated for type 2 diabetes has doubled during the last 12 years, an increase that, so far, has not begun to slow down [3]. Diabetes is a severe risk factor for CHD death, increasing the risk among men two- to threefold and among women to three- to sixfold $[4,5]$. In principle, the elevated risk of CHD death in diabetic individuals can be due either to increased incidence of acute coronary syndrome (ACS) events or increased case fatality rates or both.

Studies have shown that the incidence of ACS events is increased in diabetic individuals [6]. Earlier research also showed that the case fatality rates for ACS events in 
diabetic individuals is elevated and that the prognosis is worse than in non-diabetic persons [7-10]. Some studies have suggested that the prognosis for diabetic women after an acute myocardial infarction is worse than that for diabetic men [11].

Studies on time trends have suggested that declines in heart disease mortality rates are smaller in diabetic than in non-diabetic individuals [12]. However, the literature on time trends in case fatality rates for ACS among persons with diabetes is conflicting. It is well established that the acute treatment of ACS patients has improved substantially during the last two decades, accompanied by advances in secondary prevention measures among ACS survivors. It is, however, unclear to what extent diabetic patients have benefited from this favourable general development. Studies from the USA, Sweden and UK have suggested that the trends have been less favourable in diabetic than in nondiabetic ACS patients [12-14]. These studies also indicate that development has been very slow in diabetic women. Results conflicting with the above have also been reported, with researchers from Ontario, Canada, and from Framingham, USA, reporting similar per cent reductions in the incidence and mortality rates for diabetic and non-diabetic patients incurring an ACS or a stroke $[15,16]$.

The aim of the present study was to examine, using data on all known diabetic patients in Finland from 1992 to 2002, whether the case fatality rates for a first ACS event among patients treated for type 2 diabetes have changed. We analysed trends in case fatality rates for three periods in relation to the ACS event: (1) prehospital case fatality (sudden cardiac deaths); (2) total 28-day case fatality (days 0-27, including prehospital deaths); and (3) 1-year case fatality for 28-day survivors (i.e. days 28 to 364). The trends in patients with type 2 diabetes were compared with corresponding trends among all patients in the country without known diabetes.

\section{Methods}

Data sources Data for this study originated from a record linkage of several countrywide healthcare registers. The first was the Drug Reimbursement Registers of the National Social Insurance Institute. In Finland, all patients with diabetes received hypoglycaemic medications free of charge during the study period. To receive this 'special reimbursement', the patient needs to obtain from his/her physician a statement documenting the clinical and laboratory findings that have led to the diagnosis of diabetes. This statement is then reviewed by an expert physician of the Social Insurance Institute before the special reimbursement is granted. The Social Insurance Institute keeps a register of all patients entitled to special reimbursements. The National
Social Insurance Institute requires that before a special reimbursement can be paid, the patient must have been treated with strict diet for half a year. However, patients with very high blood sugar often receive hypoglycaemic medicines earlier. These are reimbursed by the Social Insurance Institute at the standard rate (about half the price). Such standard-rate reimbursements have been registered since 1994. It should, however, be noted that the registers of the Social Insurance Institute do not include diabetic patients treated by diet only. They also do not include permanently institutionalised patients who receive their medications from their institutes. The second register used is the National Hospital Discharge Register of the National Research and Development Centre for Welfare and Health. All hospitalisations in Finland are included in this register. The physician in charge of treatment records up to four diagnoses for each hospitalisation using the International Classification of Diseases (ICD) codes. Before 1996, ICD-9 (www.icd9data.com/2007/Volume1/240-279/ 250-259/250/default.htm) was used in Finland; since the beginning of 1996 ICD-10 (www.who.int/classifications/ $\mathrm{icd} / \mathrm{en} /$ ) has been used. The third healthcare register accessed was the National Causes of Death Register of Statistics Finland. All deaths of Finnish citizens and permanent residents are included in this register. The physician in charge of treatment codes the underlying and direct cause of death using ICD codes. The coding is then checked and revised if necessary by a nosologist working under the guidance of a specialist in forensic medicine at Statistics Finland. Cardiovascular diagnoses in the Finnish Hospital Discharge Register and in the Causes of Death Register have recently been validated and were found to be reliable [17].

The whole population of Finland (about 5.2 million inhabitants) is covered in the registers listed above. These registers can be linked together on an individual basis using the personal identification code (ID), which is unique to every permanent resident of Finland. Here, after the record linkage procedures had been performed, the personal ID was replaced by an artificial study ID to create an anonymous data set for analyses. The Ethical Committee of the National Public Health Institute approved the study.

Identification of diabetic patients and type of diabetes All patients who had received special reimbursements for hypoglycaemic medication between 1964 and 2002 or had received standard reimbursement for hypoglycaemic medication between 1994 and 2002 were identified from the drug reimbursement registers (Anatomic Therapeutic Chemical code A10). Similarly, all persons hospitalised between 1988 and 2002 and for whom diabetes was mentioned as one of the diagnoses (ICD-9 codes 250, ICD-10 codes E10-E14) were included. The date of first 
reimbursement or first diabetes diagnosis was taken as the 'incidence date' of diabetes. The Electronic supplementary material (ESM) Fig. 1 shows a graphical presentation of how study data were compiled. A more detailed description of how individuals with diabetes were identified is also available [18].

The type of diabetes was determined on the basis of age at the time of first diagnosis and the type of treatment given. Patients who were $<30$ years of age and treated with insulin only or in combination with metformin, as well as those who were aged between 30 and 40 years when treatment with insulin only began were considered to have type 1 diabetes. In addition, patients with diabetes who were $<30$ years of age and in chronic institutional care were considered to have type 1 diabetes, if the type of medical treatment was unknown. All others were considered to have type 2 diabetes. Overall, 31,725 persons $(12.5 \%$ of all identified diabetic persons) were considered to have type 1 diabetes and were excluded from the present study.

Identification of the first acute coronary syndrome Cases of ACS (myocardial infarction, unstable angina pectoris and coronary death) among all persons treated for type 2 diabetes were identified from the National Hospital Discharge Register and the Causes of Death Register between 1988 and 2002. In practice, all patients with symptomatic ACS are treated in hospitals in Finland. We used the ICD-9 codes 410 and 4110, and the ICD-10 codes I20.0, I21 and I22 for case identification in the National Hospital Discharge Register. For fatal cases, we used ICD-9 codes 410-414 and 798, and ICD-10 codes I20-I25, I46, R96 and R98 in the Causes-of-Death Register.

We excluded all persons who had had an ACS before diabetes was mentioned for the first time in the registers $(n=6,801)$. We also excluded all those who were living abroad according to the reimbursement register markings $(n=11)$. Five persons were excluded because of illogical data in the registers (hospital discharge records after death).

The study period for trend analyses included the years 1992 to 2002. For 1 year survival, however, 2001 was the last year included. First ACS was defined as no prior hospitalisation for ACS in the National Hospital Discharge Register during the preceding 4 years. The period of 4 years was chosen because for the year 1992 we could check back the years 1991, 1990, 1989 and 1988. This 4 year period was retained for the later study years to avoid creating systematic bias. We estimated from our material that this 4 year period left us with about $8 \%$ falsely identified 'first' ACS events. A 2 year rule would have given us about $15 \%$ falsely identified 'first' ACS events; a 7 year rule would have left us with about 3\% false 'first' ACS events. Thus the 4 year period was chosen as the best available option to standardise trend estimates for earlier ACS events.
Outcomes Coronary death (ICD codes as mentioned above for ACS) was used as the outcome for prehospital fatality. Cardiovascular disease (CVD) death was used as the outcome for 28-day case fatality and for 1 year fatality of 28-day survivors. CVD death was identified from the Causes of Death Register with ICD-9 codes 410-414, 798 and 430-438 (except 4378A), and ICD-10 codes I20-I25, I46, R96, R98, G45 and I60-I69 when these were used as the underlying or direct cause of death. For contributing causes of death we included ICD-9 codes 410 and 430-436 (except codes 4330X, 4331X, 4339X and 4349X), and ICD-10 codes I21-22 and I60-64 (except I63.6).

The comparison material For comparison, we calculated the same case fatality proportions for patients without diabetes using data from the National Cardiovascular Disease Register, which is based on record linkage of the National Hospital Discharge Register and the National Causes of Death Register. This register covers all ACS events in Finland that have led to hospitalisation or death. The register has been described in detail previously $[19,20]$ and summary tables as well as methodological background are available on the Internet [21]. The same ICD codes and the same definition of first ACS events were used in this comparison material as in the diabetic material. Since we had no personal ID code available in our diabetes register, we used probability-based linkage of our diabetes register and the National Cardiovascular Disease Register to identify and remove diabetic persons from the National Cardiovascular Disease Register. For 45 persons $(0.1 \%$ of the diabetic patients) the linkage failed and they were excluded from the comparison material. The remaining 191,403 persons were all patients with a first ACS and without clinically known diabetes in Finland during the study period 1992-2002. The annual numbers of ACS patients in Finland, divided by diabetes status and sex, are shown in ESM Table 1.

Statistical methods The case fatality proportions of first ACS events were computed separately by sex and age for the age groups 35 to 64 years, 65 to 74 years, 75 to 84 years and 85 to 94 years. Grouping was based on age at the time of the ACS. Patients who were younger than 35 and older than 94 at the time of ACS were excluded. The fatality proportions were age-standardised using weights derived from the age distribution of myocardial infarction patients in the myocardial infarction registers of the WHO Monitoring Trends and Determinants on Cardiovascular Diseases (MONICA) Project, extending the weights to higher age groups as described previously [22].

The trends in prehospital CHD deaths were analysed using logistic regression and odds ratios (OR, per 1 year increment in time) since there was no follow-up time for 
these events. The variables of main interest were the study year, diabetes status $(0=$ non-diabetic, $1=$ type 2 diabetes $)$ and the study year by diabetes status interaction, which was used to evaluate whether the case fatality trends differed between non-diabetic persons and persons with type 2 diabetes. The models were further adjusted for age in 5-year age groups and the university hospital district. When analysing trends in total 28-day CVD case fatality and 28-364 day CVD case fatality, we took the survival times into account by using Cox proportional hazards regression and HR. Otherwise the modelling was similar to that for prehospital deaths explained above. The time scale for Cox models on 28-day case fatality rates started from date of hospitalisation or from date of sudden death. The statistical analyses were carried out using SAS software version 9.1.3 (SAS, Chicago, IL, USA).

\section{Results}

We identified 222,940 patients aged 35 to 94 years with type 2 diabetes. Of them, 18,076 men and 21,295 women suffered their first ACS during the years 1992 to 2001. Almost two thirds of them died of cardiovascular causes within a year after the first ACS event (Table 1). Comparison of patients with type 2 diabetes and those without diabetes showed that fatality during the first year was clearly higher among persons with type 2 diabetes than among those without diabetes $(65.2 \%$ vs $56.5 \%$, i.e. 8.7 percentage points higher, for men; $61.0 \%$ vs $48.3 \%$, i.e. 12.7 percentage points higher, for women).

Prehospital case fatality rates declined over time both among patients with type 2 diabetes and among nondiabetic ACS patients (Fig. 1). Declining trends were seen in both sexes in all four age groups. Testing of diabetes by study year interactions showed that the trends in type 2 diabetes patients did not differ from those in non-diabetic patients, except for women aged 85 to 94 years, where the data suggested a steeper decline in diabetic women (Table 2). Prehospital case fatality rates were higher among men than women, but the difference disappeared after the age of 85 . In the 35 to 64 year age group. the OR for diabetes was non-significantly higher than 1.0 , but after the age of 65 it was significantly less than 1.0, becoming progressively smaller in the older age groups.

The 28-day case fatality rates of ACS declined in patients with type 2 diabetes and in non-diabetic patients in both sexes and in all age groups (Fig. 2). Proportional hazards regression analysis demonstrated that the declining trends were significant and did not differ between patients with type 2 diabetes and non-diabetic patients (Table 3 ). Type 2 diabetes was associated with a 34\% higher 28-day case fatality rate in men (vs non-diabetic) and a $69 \%$ higher case fatality rate in women (vs non-diabetic) in the 35 64 years age group. In the older age group the corresponding excess case fatality rate became progressively smaller.

Among the 28-day survivors, the age-standardised cardiovascular fatality rate during days 28 to 364 decreased significantly and quite substantially among persons with type 2 diabetes and among non-diabetic patients with a first ACS (Fig. 3, Table 3). Again, the trends did not differ between patients with type 2 diabetes and non-diabetic patients. However, the fatality rate was considerably higher in patients with type 2 diabetes, namely $187 \%$ higher in men and $484 \%$ in women aged 35 to 64 years. Even in the 85-94 years age group, the 28 to 364 day case fatality rate was $56 \%$ higher among diabetic men and $45 \%$ higher among diabetic women than among non-diabetic counterparts

\section{Discussion}

Using large countrywide materials, our study showed that patients with type 2 diabetes have experienced a similar improvement to non-diabetic patients in case fatality rates for a first ACS event. However, the level of case fatality has remained significantly higher in diabetic than in non-diabetic individuals. Of particular concern is the 28 to 364 day period, where the case fatality among patients with type 2 diabetes was more than twice as high as in non-diabetic patients. As a whole, over $60 \%$ of patients with type 2 diabetes and a first ACS died of CVD causes within 1 year after the ACS event. Men had higher case fatality rates than women, both among patients with type 2 diabetes and among non-diabetic patients. However, except for prehospital deaths, diabetic women had the same or even higher case fatality rates than non-diabetic men. For example, in the full agerange of 35 to 94 years, $61.0 \%$ of women with type 2 diabetes had died of cardiovascular causes 1 year after their first ACS. Among non-diabetic men, the corresponding proportion was $56.5 \%$.

The main strength of this study is that it covers the total population of Finland with symptomatic ACS events over a period of 11 years. It thus had a large number of patients with type 2 diabetes and was able to produce precise trend estimates with narrow confidence intervals. We were also able to identify first ACS events with fair accuracy. This made the case mix more homogenous and also improved comparability over time between patients with 2 diabetes and those without diabetes.

Several limitations of the study should be mentioned. First, we were able to identify only those diabetic patients treated with hypoglycaemic medication or hospitalised and 
Table 1 Comparison of Finnish type 2 diabetic with non-diabetic patients for first ACS, and numbers and proportions with fatal outcome

\begin{tabular}{|c|c|c|c|c|}
\hline \multirow[t]{2}{*}{ Variables } & \multicolumn{2}{|l|}{ Type 2 diabetes } & \multicolumn{2}{|l|}{ Non-diabetic } \\
\hline & Men & Women & Men & Women \\
\hline \multicolumn{5}{|l|}{ Age group 35-74 years } \\
\hline$n$ & 92,371 & 85,601 & & \\
\hline First $\operatorname{ACS}(n)^{\mathrm{a}}$ & 12,358 & 7,038 & 70,714 & 26,106 \\
\hline \multicolumn{5}{|l|}{ ACS with fatal outcome ${ }^{\mathrm{b}}$} \\
\hline Prehospital $(n)$ & 3,274 & 1,229 & 20,877 & 5,216 \\
\hline Prehospital, \% $(95 \% \mathrm{CI})^{\mathrm{c}}$ & $27.1(27.0-27.2)$ & $18.7(18.5-18.8)$ & $29.7(29.7-29.8)$ & $19.8(19.7-19.8)$ \\
\hline Total 28 day $(n)$ & 6,269 & 3,131 & 28,336 & 8,300 \\
\hline Total 28 day, $\%(95 \% \mathrm{CI})^{\mathrm{c}}$ & $50.3(50.2-50.5)$ & $42.1(41.9-42.2)$ & $41.0(41.0-41.1)$ & $30.1(30.0-30.1)$ \\
\hline Total 1 year $(n)^{\mathrm{d}}$ & 6,563 & 3,544 & 28,864 & 8,825 \\
\hline Total 1 year, $\%(95 \% \mathrm{CI})^{\mathrm{c}}$ & $56.5(56.4-56.6)$ & $50.3(50.2-50.5)$ & $44.5(44.4-44.5)$ & $33.0(32.9-33.0)$ \\
\hline \multicolumn{5}{|l|}{ Age group 75-94 years } \\
\hline$n$ & 13,731 & 31,237 & & \\
\hline First $\operatorname{ACS}(n)^{\mathrm{a}}$ & 7,715 & 16,301 & 37,564 & 57,019 \\
\hline \multicolumn{5}{|l|}{ ACS with fatal outcome ${ }^{b}$} \\
\hline Prehospital (n) & 1,513 & 2,779 & 11,285 & 15,318 \\
\hline Prehospital, \% $(95 \% \mathrm{CI})^{\mathrm{c}}$ & $19.4(19.3-19.5)$ & $17.0(17.0-17.1)$ & $30.2(30.1-30.2)$ & $26.0(26.0-26.1)$ \\
\hline Total 28 day $(n)$ & 4,825 & 10,047 & 22,714 & 33,852 \\
\hline Total 28 day, $\%(95 \% \mathrm{CI})^{\mathrm{c}}$ & $64.5(64.4-64.6)$ & $61.5(61.4-61.6)$ & $61.5(61.4-61.5)$ & $56.8(56.7-56.8)$ \\
\hline Total 1 year $(n)^{\mathrm{d}}$ & 5,140 & 10,995 & 24,131 & 35,869 \\
\hline Total 1 year, $\%(95 \% \mathrm{CI})^{\mathrm{c}}$ & $74.8(74.7-74.9)$ & $72.6(72.5-72.6)$ & $69.6(69.6-69.7)$ & $65.1(65.1-65.1)$ \\
\hline \multicolumn{5}{|l|}{ All type 2 diabetes } \\
\hline$n$ & 106,102 & 116,838 & & \\
\hline First $\operatorname{ACS}(n)^{\mathrm{a}}$ & 20,073 & 23,339 & 108,278 & 83,125 \\
\hline First $\operatorname{ACS}(n)^{\mathrm{d}}$ & 18,076 & 21,295 & 99,518 & 75,978 \\
\hline ACS with fatal outcome days $0-364(n)$ & 11,703 & 14,539 & 52,995 & 44,694 \\
\hline ACS with fatal outcome days $0-364, \%(95 \% \mathrm{CI})^{\mathrm{c}}$ & $65.2(65.0-65.5)$ & $61.0(60.4-61.5)$ & $56.5(56.4-56.6)$ & $48.3(48.2-48.5)$ \\
\hline
\end{tabular}

All persons with known type 2 diabetes mellitus in Finland were compared with non-diabetic patients identified from the National Cardiovascular Disease Register for the period 1992-2002

${ }^{\text {a }}$ First ACS between 1 January 1992 and 30 November 2002

${ }^{\mathrm{b}}$ Fatal outcome means death from CVD causes as indicated by ICD codes (see Methods)

${ }^{\mathrm{c}}$ Fatality proportions are age-standardised to the age distribution of myocardial infarction patients in the WHO MONICA Project [22]

${ }^{\mathrm{d}}$ First ACS in persons with type 2 diabetes between 1 January 1992 and 31 December 2001 (35-74 year age group $n=11,225$ [men], $n=6,535$ [women]; 75-94 year age group $n=6,851$ [men], $n=14,760$ [women]) and first ACS in non-diabetic persons (35-74 year age group $n=65,390$ [men], $n=24,210$ [women]; 75-94 year age group $n=34,128$ [men], $n=51,768$ [women])

had hardly any information on patients whose diabetes was being treated by diet only. According to the literature, $16 \%$ to $30 \%$ of patients with type 2 diabetes are treated by diet in Finland $[23,24]$. Thus, the diabetic patients in our study represent approximately $70 \%$ to $84 \%$ of all patients diagnosed with type 2 diabetes and are likely to feature the more severe end of the diabetes spectrum. It should be pointed out, however, that the main focus of our study was on estimating trends in case fatality rates for ACS among patients with type 2 diabetes; such trends are likely to be less affected by the limitations mentioned above than the levels of case fatality.
One possible explanation for the declining case fatality rate for ACS among persons with type 2 diabetes is that the case mix of diabetic patients may have changed over time. The definition of diabetes changed during the study period [25]. Furthermore, it is possible that towards the end of our study period type 2 diabetes was diagnosed earlier and treated with hypoglycaemic medication earlier than in the early 1990s. This argument is supported by the increased use of hypoglycaemic medications [26, 27]. Accordingly, the later years close to 2002 may include more patients with a shorter history of diabetes and fewer complications. This could contribute to the improved prognosis. It should be 
Fig. 1 Age-standardised prehospital case fatality rates for first ACS event in patients with type 2 diabetes (black squares, men; white squares, women) and in all non-diabetic patients (black triangles, men; white triangles, women) in Finland from 1992 to 2002. The age groups shown are (a) 35 to 64 years, (b) 65 to 74 years, (c) 75 to 84 years and (e) 85 to 94 years. For corresponding ORs per 1 year increment in time, see Table 2
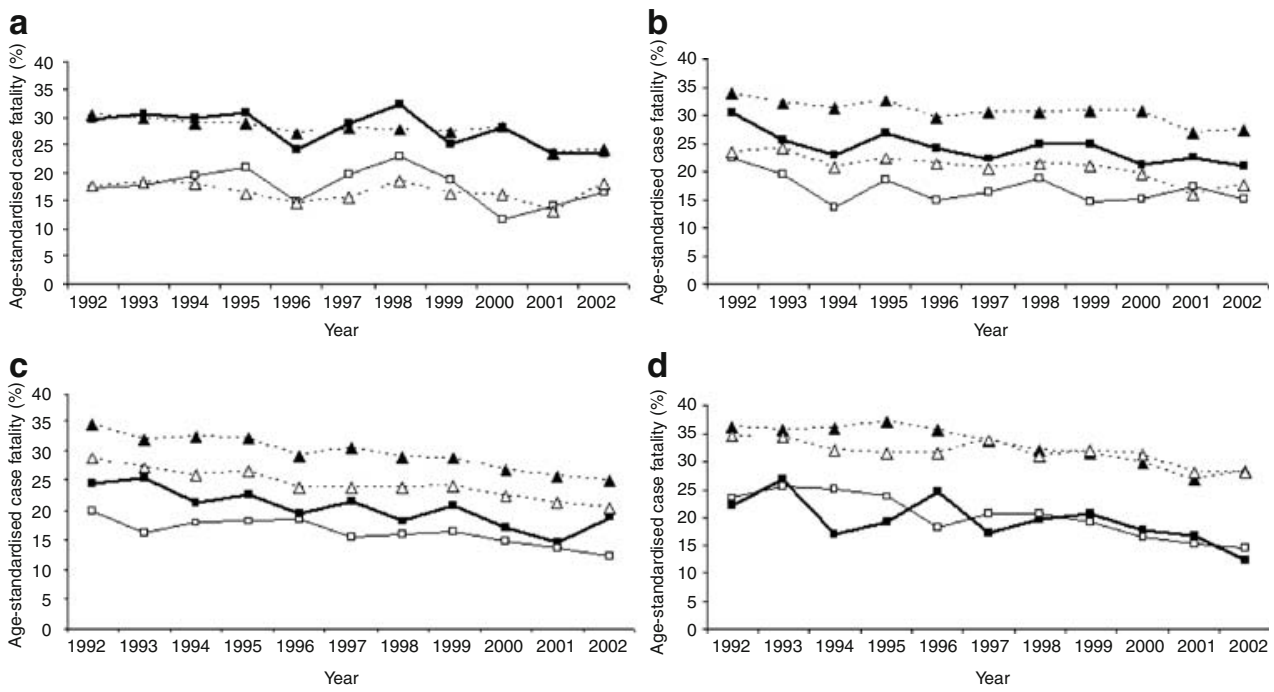

pointed out, however, that although the absolute case fatality rate declined significantly in patients with type 2 diabetes, the HR comparing diabetic patients with nondiabetic patients remained constant during the study period.

Earlier reports, including the National Health and Nutrition Examination Surveys in the USA, have suggested that CHD and total mortality rates have not declined among diabetic individuals to as favourable an extent as among non- diabetic persons $[7,28]$. In particular, women with type 2 diabetes seemed to have had a less favourable development than male counterparts and non-diabetic individuals. Similar findings were reported from the Swedish MONICA myocardial infarction register study, which found no positive trends among diabetic patients in first myocardial infarctions, recurrent myocardial infarctions and myocardial infarction case fatality during the period from 1989 to 2000 ,
Table 2 Odds ratios by sex and age group for prehospital coronary death in all patients with clinically known type 2 diabetes and first-ever ACS in Finland from 1992 to 2002

Values are ORs $(95 \% \mathrm{CI})$. ORs were adjusted for age and university hospital district

The reference category for diabetes is all patients in the country with their first ACS and without clinically known diabetes. The OR for study year is per 1 year increment. For numbers of fatal and all first ACS events, see Table 1

${ }^{a}$ This value was $0.43(0.33$ $0.55)$ for $2002(p<0.0001)$

\begin{tabular}{|c|c|c|c|c|}
\hline \multirow[t]{2}{*}{ Age group and predictor } & \multicolumn{2}{|l|}{ Men } & \multicolumn{2}{|l|}{ Women } \\
\hline & OR $(95 \% \mathrm{CI})$ & $p$ value & OR $(95 \% \mathrm{CI})$ & $p$ value \\
\hline \multicolumn{5}{|l|}{$35-64$ years } \\
\hline$n$ & 43,042 & & 10,143 & \\
\hline Study year & $0.97(0.96-0.98)$ & $<0.0001$ & $0.97(0.95-1.00)$ & 0.023 \\
\hline Diabetes & $1.05(0.92-1.20)$ & 0.480 & $1.21(0.91-1.61)$ & 0.180 \\
\hline Study year $\times$ diabetes & $1.00(0.98-1.02)$ & 0.778 & $0.98(0.94-1.02)$ & 0.386 \\
\hline \multicolumn{5}{|l|}{ 65-74 years } \\
\hline$n$ & 40,030 & & 23,001 & \\
\hline Study year & $0.97(0.96-0.98)$ & $<0.0001$ & $0.97(0.95-0.98)$ & $<0.0001$ \\
\hline Diabetes & $0.78(0.68-0.88)$ & $<0.0001$ & $0.75(0.64-0.88)$ & $<0.0004$ \\
\hline Study year $\times$ diabetes & $0.99(0.97-1.01)$ & 0.370 & $1.01(0.99-1.04)$ & 0.422 \\
\hline \multicolumn{5}{|l|}{$75-84$ years } \\
\hline$n$ & 33,539 & & 43,718 & \\
\hline Study year & $0.96(0.95-0.97)$ & $<0.0001$ & $0.96(0.95-0.97)$ & $<0.0001$ \\
\hline Diabetes & $0.62(0.54-0.72)$ & $<0.0001$ & $0.63(0.56-0.71)$ & $<0.0001$ \\
\hline Study year $\times$ diabetes & $1.00(0.98-1.02)$ & 0.733 & $0.99(0.98-1.01)$ & 0.562 \\
\hline \multicolumn{5}{|l|}{ 85-94 years } \\
\hline$n$ & 11,740 & & 29,602 & \\
\hline Study year & $0.95(0.93-0.97)$ & $<0.0001$ & $0.95(0.94-0.96)$ & $<0.0001$ \\
\hline Diabetes & $0.50(0.36-0.68)$ & $<0.0001$ & $0.77(0.65-0.91)^{\mathrm{a}}$ & 0.002 \\
\hline Study year $\times$ diabetes & $1.00(0.96-1.05)$ & 0.991 & $0.95(0.93-0.97)$ & $<0.0001$ \\
\hline
\end{tabular}


Fig. 2 Age-standardised 0 to 27 day case fatality (including prehospital period) for first ACS event in patients with type 2 diabetes (black squares, men; white squares, women) and in all non-diabetic (black triangles, men; white triangles, women) patients in Finland from 1992 to 2002. The age groups shown are (a) 35 to 64 years, (b) 65 to 74 years, (c) 75 to 84 years and (d) 85 to 94 years. For corresponding HRs per 1 year increment in time, see Table 3
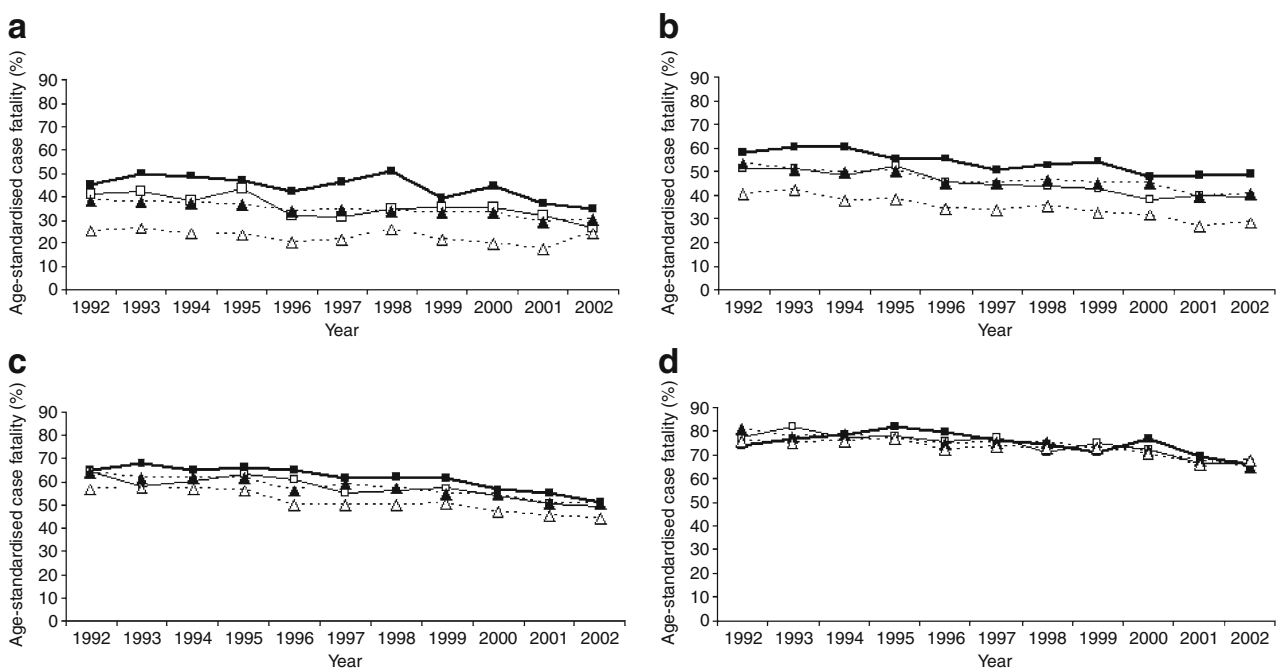

while, over the same time, all these indicators developed positively in the non-diabetic population [13]. Furthermore, investigators from $\mathrm{UK}$ have reported a comparison of treatment given to patients with and without diabetes who sustained a myocardial infarction in 1995 or 2003. Involvement of cardiologists, provision of secondary prevention agents and early revascularisation rates improved in both groups. The 30 day mortality rate was significantly improved in both groups, but at 18 months the mortality rate in the diabetic group was unchanged [14].

On the other hand, investigators of the Framingham Heart Study reported that adults with and without diabetes have benefited similarly during the decline in CVD rates over the last several decades [16]. However, this paper reported incidence of CVD events but not case fatality rates. Another study from the USA reported a comparison

Table 3 Hazard ratios for cardiovascular death during 0 to 27 and 28 to 364 day periods after the first ACS event in all patients with clinically known type 2 diabetes and all non-diabetic ACS patients in Finland between 1992 and 2002

\begin{tabular}{|c|c|c|c|c|c|c|c|c|}
\hline \multirow[t]{3}{*}{ Age group and predictor } & \multicolumn{4}{|l|}{$0-27$ days } & \multicolumn{4}{|l|}{ 28-364 days } \\
\hline & \multicolumn{2}{|l|}{ Men } & \multicolumn{2}{|l|}{ Women } & \multicolumn{2}{|l|}{ Men } & \multicolumn{2}{|l|}{ Women } \\
\hline & $\operatorname{HR}(95 \% \mathrm{CI})$ & $p$ value & HR $(95 \% \mathrm{CI})$ & $p$ value & $\operatorname{HR}(95 \% \mathrm{CI})$ & $p$ value & $\operatorname{HR}(95 \% \mathrm{CI})$ & $p$ value \\
\hline $35-64$ years $(n)$ & 15,663 & & 2,697 & & 846 & & 197 & \\
\hline Study year & $0.97(0.97-0.98)$ & $<0.0001$ & $0.97(0.96-0.99)$ & $<0.0001$ & $0.93(0.90-0.95)$ & $<0.0001$ & $0.93(0.87-0.98)$ & 0.008 \\
\hline Diabetes & $1.34(1.24-1.45)$ & $<0.0001$ & $1.69(1.44-1.97)$ & $<0.0001$ & $2.87(2.19-3.75)$ & $<0.0001$ & $5.84(3.70-9.23)$ & $<0.0001$ \\
\hline Study year $\times$ diabetes & $1.00(0.98-1.01)$ & 0.751 & $0.99(0.96-1.02)$ & 0.492 & $0.98(0.93-1.03)$ & 0.412 & $0.94(0.85-1.03)$ & 0.167 \\
\hline $65-74$ years $(n)$ & 19,150 & & 8,792 & & 1,800 & & 1,165 & \\
\hline Study year & $0.97(0.97-0.98)$ & $<0.0001$ & $0.96(0.95-0.96)$ & $<0.0001$ & $0.94(0.92-0.95)$ & $<0.0001$ & $0.91(0.84-0.93)$ & $<0.0001$ \\
\hline Diabetes & $1.18(1.10-1.25)$ & $<0.0001$ & $1.28(1.18-1.38)$ & $<0.0001$ & $2.21(1.83-2.67)$ & $<0.0001$ & $2.43(1.99-2.96)$ & $<0.0001$ \\
\hline Study year $\times$ diabetes & $1.00(0.99-1.01)$ & 0.723 & $1.01(1.00-1.03)$ & 0.152 & $1.00(0.96-1.03)$ & 0.811 & $1.04(1.00-1.08)$ & 0.077 \\
\hline $75-84$ years $(n)$ & 19,299 & & 23,141 & & 2,435 & & 3,460 & \\
\hline Study year & $0.97(0.96-0.97)$ & $<0.0001$ & $0.97(0.96-0.97)$ & $<0.0001$ & $0.94(0.93-0.95)$ & $<0.0001$ & $0.93(0.92-0.94)$ & $<0.0001$ \\
\hline Diabetes & $1.09(1.02-1.17)$ & 0.013 & $1.12(1.06-1.18)$ & $<0.0001$ & $1.49(1.25-1.78)$ & $<0.0001$ & $1.65(1.45-1.88)$ & $<0.0001$ \\
\hline Study year $\times$ diabetes & $1.00(0.99-1.01)$ & 0.865 & $1.00(1.00-1.01)$ & 0.404 & $1.00(0.98-1.03)$ & 0.791 & $1.02(0.99-1.04)$ & 0.189 \\
\hline $85-94$ years $(n)$ & 8,452 & & 21,087 & & 936 & & 2,575 & \\
\hline Study year & $0.97(0.96-0.98)$ & $<0.0001$ & $0.98(0.98-0.99)$ & $<0.0001$ & $0.96(0.94-0.96)$ & 0.0008 & $0.96(0.94-0.97)$ & $<0.0001$ \\
\hline Diabetes & $0.98(0.86-1.12)$ & 0.787 & $1.07(1.00-1.15)$ & 0.053 & $1.56(1.07-2.28)$ & 0.022 & $1.45(1.19-1.76)$ & 0.0002 \\
\hline Study year $\times$ diabetes & $1.01(0.99-1.03)$ & 0.482 & $0.99(0.98-1.00)$ & 0.194 & $0.97(0.92-1.03)$ & 0.317 & $0.98(0.95-1.01)$ & 0.138 \\
\hline
\end{tabular}

Hazard ratios are given with $(95 \% \mathrm{CI})$ and are adjusted for age and university hospital district. Hazard ratios for study year are per 1 year increment; reference category for diabetes is non-diabetic patients

Numbers of fatal events, see Table 1; corresponding trend lines, see Figs 2 and 3 
Fig. 3 Age-standardised 28 to 364 day case fatality of the 28-day survivors of first ACS event in patients with type 2 diabetes (black squares, men; white squares, women) and in all non-diabetic (black triangles, men; white triangles, women) patients in Finland from 1992 to 2002. The age groups shown are (a) 35 to 64 years, (b) 65 to 74 years, (c) 75 to 84 years and (d) 85 to 94 years. For corresponding HRs per 1 year increment in time, see Table 3
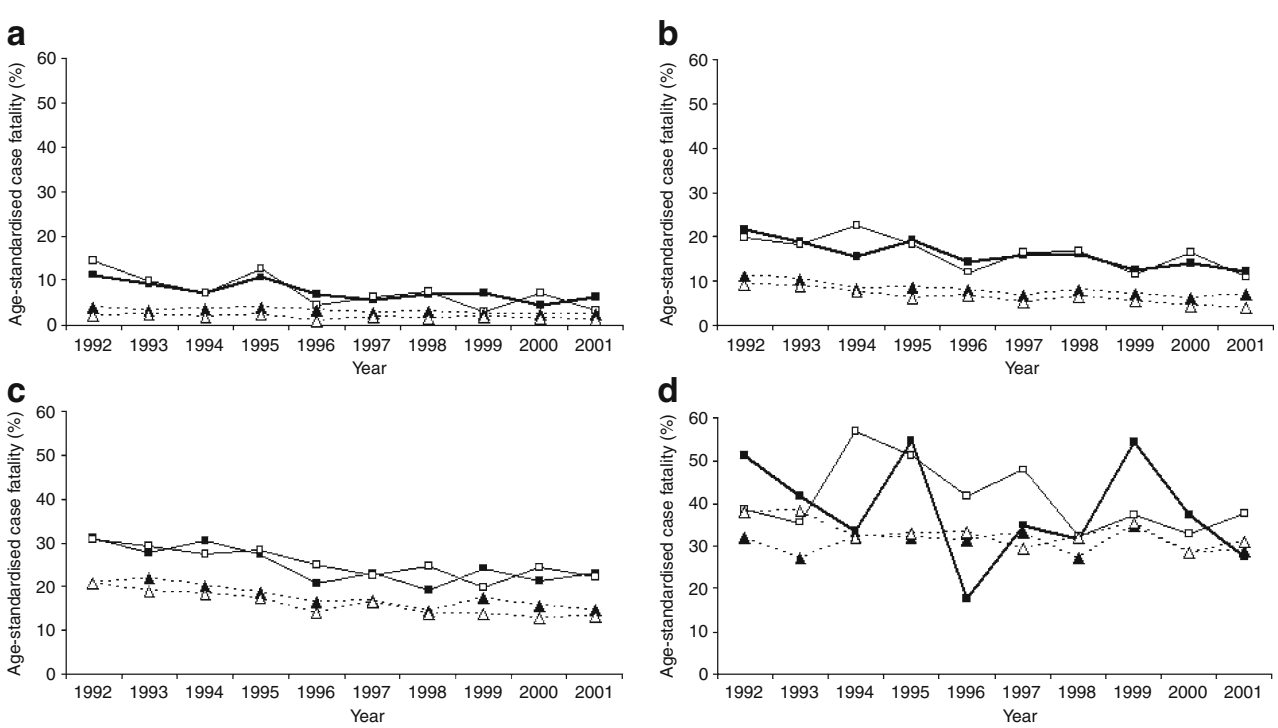

of trends in post myocardial infarction mortality rates among patients with and without diabetes from 1990 through to 1997 [29]. It showed a $35 \%$ higher 1 year mortality rate among diabetic than among non-diabetic patients. Age-adjusted 1 year mortality rates showed a significant downward trend regardless of diabetes status (4.9\% decrease in odds of mortality per year, $p<0.001)$. Our present study agrees with the similarity in declining trends, but suggests that there could be an even bigger difference in case fatality rates between type 2 diabetes patients and those without diabetes. In an earlier study, we compared 1 year mortality between diabetic and nondiabetic 28-day survivors of myocardial infarction and found a hazard ratio of 1.97 for diabetic men and 4.17 for diabetic women in the 25 to 64 age group [7].

A large register study from Canada compared the incidence of myocardial infarction in diabetic and nondiabetic populations from 1992 to 2000, showing a greater reduction among diabetic than among non-diabetic patients $(-15.1 \%$ vs $-9.1 \%, p<0.0001)$. The corresponding reductions for deaths from myocardial infarction were $-44.1 \%$ and $-33.2 \%(p=0.1)$. At the same time, the number of patients with diabetes increased from 405,471 to 670,602 , so although the incidence rates fell, the number of myocardial infarctions increased by $44.6 \%$ and the number of myocardial infarction deaths increased by $17.2 \%$ [15]. A recent study from Sweden showed that the age-adjusted 10 -year survival rate for men with diabetes increased from $41.4 \%$ between 1980 and 1984 to $51.5 \%$ between 1995 and 1999. The corresponding improvement in survival was even larger for women, namely from $43.7 \%$ to $61.0 \%$ [30]. Although these Swedish figures reflect overall survival rates, they are broadly consistent with our findings since CVD is one of the most important causes of death among diabetic patients.
Generally, studies in the 1990s and since 2000 have reported more favourable trends in survival of patients with diabetes after an ACS event than studies in the 1980s. One reason for this could be an earlier and more active treatment of risk factors. We found equally positive developments in the results of patients with type 2 diabetes and without diabetes in acute treatment of myocardial infarction and 1 year survival, the latter reflecting the effects of secondary prevention. However the 1 year case fatality rate for 28-day survivors with type 2 diabetes mellitus was still double that of the non-diabetic population.

Interestingly, after the age of 65 years, patients with type 2 diabetes had a lower prehospital case fatality than those without diabetes. However, in the 35 to 64 year age group diabetic patients had a non-significantly higher prehospital case fatality rate. After the age of 65, men and women with type 2 diabetes had a significantly lower OR for death than non-diabetic individuals. This could suggest that a proportion of elderly persons with type 2 diabetes may already have been hospitalised for one reason or another when they had their first ACS event. Other explanations could be that diabetic patients are more likely to seek professional help when they experience symptoms and therefore would call for help earlier. Against this background, the finding of a more steeply declining trend in prehospital case fatality rates among old women with type 2 diabetes than among their non-diabetic counterparts should be interpreted with caution. It may reflect changing hospitalisation policies rather than improving preventive treatment in elderly women with diabetes.

In conclusion, our study demonstrates that patients with type 2 diabetes have experienced similar improving trends to non-diabetic patients in case fatality rates after a first ACS. However, despite the improving trends, the relative risk of fatal outcome in type 2 diabetes has remained the 
same during the study period. Of particular concern is the period after the acute stage, i.e. days 28 to 364 , where the risk of fatal outcome was twice as high in patients with type 2 diabetes as in non-diabetic patients. This indicates the need for more effective secondary prevention measures after an ACS in diabetic individuals.

Acknowledgements This study was supported by a grant from the Finnish Diabetes Research Foundation (to K. M. Winell) and from the Finnish Foundation for Cardiovascular Research (V. V. Salomaa).

Duality of interest The authors declare that there is no duality of interest associated with this manuscript.

\section{References}

1. International Diabetes Federation (2006) Diabetes atlas, 3rd edn. Available from www.eatlas.idf.org, accessed 28 June 2008

2. Carstensen B, Kristensen J, Ottosen P, Borch-Johnsen K, on behalf of the steering group of the National Diabetes Register (2008) The Danish National Diabetes Register: trends in incidence, prevalence and mortality. Diabetologia 51:2187-2196

3. Winell K, Reunanen A (2006) Diabetes barometer 2005. Available at www.diabetes.fi/sivu.php?artikkeli_id $=2081$, accessed 30 June 2008

4. Kanaya AM, Grady D, Barrett-Connor E (2002) Explaining the sex difference in coronary heart disease mortality among patients with type 2 diabetes mellitus: a meta-analysis. Arch Intern Med 162:1737-1745

5. Forssas EH, Keskimäki IT, Reunanen AR, Koskinen SV (2008) Coronary heart disease among diabetic and nondiabetic peoplesocioeconomic differences in incidence, prognosis and mortality. J Diabetes Complications 22:10-17

6. Laakso M (1999) Hyperglycemia and cardiovascular disease in type 2 diabetes. Diabetes 48:937-942

7. Miettinen H, Lehto S, Salomaa V et al (1998) Impact of diabetes on mortality after the first myocardial infarction. The FINMONICA Myocardial Infarction Register Study Group. Diabetes Care 21:69-75

8. Koek HL, Soedamah-Muthu SS, Kardaun JW et al (2007) Shortand long-term mortality after acute myocardial infarction: comparison of patients with and without diabetes mellitus. Eur J Epidemiol 22:883-888

9. Svensson AM, Dellborg M, Abrahamsson P et al (2007) The influence of a history of diabetes on treatment and outcome in acute myocardial infarction, during two time periods and in two different countries. Int J Cardiol 31:319-325

10. Donahoe SM, Stewart GC, McCabe CH et al (2007) Diabetes and mortality following acute coronary syndromes. JAMA 298:765775

11. Maier B, Thimme W, Kallischnigg G et al (2006) Does diabetes mellitus explain the higher hospital mortality of women with acute myocardial infarction? Results from the Berlin Myocardial Infarction Registry. J Investig Med 54:143-151

12. Gu K, Cowie CC, Harris MI (1999) Diabetes and decline in heart disease mortality in US adults. JAMA 14:1291-1297

13. Rautio A, Lundberg V, Messner T, Nasic S, Stegmayr B, Eliasson M (2005) Favourable trends in the incidence and outcome of myocardial infarction in nondiabetic, but not in diabetic, subjects: findings from the MONICA myocardial infarction registry in northern Sweden in 1989-2000. J Intern Med 258:369-377

14. Cubbon RM, Wheatcroft SB, Grant PJ, on behalf of the EMMACE (Evaluation of Methods and Management of Acute Coronary Events) Investigators et al (2007) Temporal trends in mortality of patients with diabetes mellitus suffering acute myocardial infarction: a comparison of over 3000 patients between 1995 and 2003. Eur Heart J 28:540-545

15. Booth GL, Kapral MK, Fung K, Tu JV (2006) Recent trends in cardiovascular complications among men and women with and without diabetes. Diabetes Care 29:32-37

16. Fox CS, Coady S, Sorlie PD et al (2004) Trends in cardiovascular complications of diabetes. JAMA 292:2495-2499

17. Pajunen P, Koukkunen H, Ketonen M et al (2005) The validity of the Finnish Hospital Discharge Register and Causes of Death Register data on coronary heart disease. Eur J Cardiovasc Prev Rehabil 12:132-137

18. Niemi M, Winell K (2006) Diabetes in Finland, prevalence and variation in quality of care. Available at www.diabetes.fi/tiedos ton katsominen.php?dok id=534, accessed 30 June 2008

19. Mähönen M, Salomaa V, Keskimäki I, Moltchanov V (2000) The feasibility of routine mortality and morbidity register data linkage to study the occurrence of acute coronary heart disease events in Finland. The Finnish Cardiovascular Diseases Registers (CVDR) Project. Eur J Epidemiol 16:701-711

20. Pajunen P, Pääkkönen R, Juolevi A et al (2004) Trends in fatal and non-fatal coronary heart disease events in Finland during 1991-2001. Scand Cardiovasc J 38:340-344

21. National Institute of Health and Welfare. National Cardiovascular Disease Register. Available at www.ktl.fi/portal/english/public health_monitoring__promotion/registers/cardiovascular_dis eases/, accessed 30 June 2008

22. Tunstall-Pedoe H, Kuulasmaa K, Amouyel P, Arveiler D, Rajakangas AM, Pajak A (1994) Myocardial infarction and coronary deaths in the World Health Organization MONICA Project. Registration procedures, event rates, and case-fatality rates in 38 populations from 21 countries in four continents. Circulation 90:583-612

23. Reunanen A (2004) Suomalaisten diabetes: Harvinaisuudesta kansansairaudeksi. Diabetes ja Lääkäri 6:6-11 (Article in Finnish)

24. Finnish Quality Networks. Type 2 diabetes. Information. Powerpoint presentation.Available at www.conmedic.fi/sarjat/2007/laa tumittaus/esittely_diabetes.pps\#450,14,Dia, accessed 15 January 2009 (In Finnish)

25. World Health Organisation and International Diabetes Federation (1998) Definition and diagnosis of diabetes mellitus and intermediate hyperglycemia. WHO Document Production Services, Geneva

26. No authors listed (2006) Finnish statistics on medicines. National Agency for Medicines and Social Insurance Institution, Helsinki

27. Salomaa V, Pääkkönen R, Hämäläinen $H$, Niemi M, Klaukka T (2007) Use of secondary preventive medications after the first attack of acute coronary syndrome. Eur J Cardiovasc Prev Rehabil 14:386-391

28. Gregg EW, Gu Q, Cheng YJ, Narayan KM, Cowie CC (2007) Mortality trends in men and women with diabetes, 1971 to 2000. Ann Intern Med 47:149-155

29. Kamalesh M, Subramanian U, Ariana A, Sawada S, Tierney W (2005) Similar decline in post-myocardial infarction mortality among subjects with and without diabetes. Am J Med Sci 329:228-233

30. Eliasson M, Talbäck M, Rosen M (2008) Improved survival in both men and women with diabetes between 1980 and 2004-a cohort study in Sweden. Cardiovasc Diabetol 7:32-40 